\title{
Public health pedagogy and technology as a mode of existence
}

\author{
Benjamin Williams and Jessica Lee
}

Author 1: Dr Benjamin Williams

Affiliation: School of Education and Professional Studies, Griffith University

ORCID: https://orcid.org/0000-0002-8083-7876

Author 2: Dr Jessica Lee

Affiliation: School of Medicine, Griffith University

ORCID: https://orcid.org/000o-0001-5760-2692

Keywords: Bruno Latour; modes of existence; compositionism; public health pedagogy

\begin{abstract}
In this chapter, we use Bruno Latour's research on modes of existence to study a public health pedagogy, the Healthier. Happier. campaign, as a technological being. We approached this project with the question of why critical health research is seldom translated into practice by policy makers. Analysing Healthier. Happier. as a technological being drew our attention to the compositional logic of the campaign's existence. This conceptual apparatus provides access to the interpretive key with which to better understand the often opaque and taken-for-granted process of evidence-based practice in public health pedagogies like Healthier. Happier. Latour's work on modes of existence has helped us think about the campaign's existence in ways other theories have not. Ultimately, it has provided the language and thinking tools to consider the possibility of increased engagement with critical public health literature by campaign developers.
\end{abstract}




\section{Introduction}

You know [...] you'd be foolish to think that um, um, this was just [...] an evidence based [campaign]. You know, any interventions are not just based on the evidence. [...]

There's a whole range of, you know, interactions. (Healthier. Happier. campaign worker) Bruno Latour is one of the most influential thinkers of our time. A prolific author, he has produced a large body of work on a diverse array of topics. The ideas presented in these works have been taken up by scholars across a wide range of disciplines. Consequently, Latour has become one of the most frequently cited authors in the contemporary social sciences. Yet, to date, his scholarship has had little impact in health education. In this chapter, we aim to help address this gap. Instead of drawing on Latour's well-known writing on actor-network theory (Latour, 2005), we use his recent research on modes of existence to study health pedagogies-as-technological beings. We begin by summarising the term, mode of existence, and its associated concepts. Then, we describe the characteristics of the technological mode of existence identified by Latour and the means by which it can be studied. In the penultimate section, we use this vocabulary to explore the development of the public health campaign, Healthier. Happier. This campaign interested us because it took an innovative approach to public health interventions, yet seemed to ignore, omit or overlook potentially useful critical health insights about obesity, m-health and behaviour change. To this end, Latour's work offered a means of exploring how the campaign came together and considering why these insights did not feature in it. We conclude by reflecting on the value of studying public health pedagogies in this manner.

\section{Modes of existence}

The fullest account of Latour's thinking on modes of existence can be found in An Inquiry into Modes of Existence (Latour, 2013). However, the best starting point for understanding this work is a book he wrote some twenty years earlier. In We Have Never Been Modern (Latour, 1993), Latour interrogated the 
division between Nature and Society upon which modernity is founded and the distinction it created between Modern and Premodern people. Through this investigation, he illustrated Western civilisation's ever-increasing creation of, and dependence on, hybrid beings-mixtures of natural, social and discursive phenomena whose ontological status cannot be accommodated within the tidy dualisms of modernity. According to Latour, this flaw in the metaphysics of modernity has precipitated the many crises confronting the contemporary world. It has also stymied the West's ability to respond to these challenges. We Have Never Been Modern is, therefore, the diagnosis of a problem and a description of its consequences. By contrast, An Inquiry into Modes of Existence is an attempt to develop a metaphysics better able to reconcile the values the Moderns hold dear with the way they define and defend these values to themselves and others. This metaphysics is pertinent to our research insofar as it provides a nonmodern (Latour, 1993) way of studying the role of science and technology in democracy and vice versa.

The metaphysics Latour develops in An Inquiry into Modes of Existence is underpinned by a relationist ontology (Latour, 1988). From this perspective, every entity is a consequence of its relations with other entities. Moreover, the actions and attributes of an entity are defined by its connection to the other entities with which it is associated. Thus conceived, an entity like a fish, "depends on, is constituted by, the water it swims in, the plankton or little fish that it eats, the right temperature and $\mathrm{pH}$, and so on" (Mol, 2010, p. 257). Similarly, the existence of the fish in this example has consequences for the animals it eats, the ecosystem in which it lives, the fishers who derive their livelihood from it, the scientists who study it, et cetera. Latour's relationalist ontology attunes researchers to the ways in which entities interdefine each other. It also directs researchers' attention to the processes through which entities are brought into relations with each other. Latour uses the term network to refer to these two aspects of his relationalist ontology—-that is, network (noun) as an arrangement of interdefined entities and network (verb) as an assembling of interdefining entities. In our research, Latour's 
relationalism focused us on how the public health campaign we studied came to be and continued to exist through these relations and processes of interdefinition.

Alongside relationalism, Latour's sensitivity to hybridity is another feature of his metaphysics. Latour's worldview is not built upon a priori distinctions between humans and nonhumans, facts and values, subjects and objects, or realities and constructions. Nor does it adopt the analytical convention of dividing reality into clearly bounded domains such as science, politics, economics, technology, religion, law, and so forth. Rather, the conceptual architecture Latour has developed prioritises the fuzzy middle ground between each of these poles and domains. In this way, it helps researchers appreciate the ontologically diverse array of associating entities that are critical to the existence of any given entity. Moreover, it provides researchers with a means of studying situations that seldom respect domain boundaries. For example, this concern with hybridity has allowed Latour to highlight the heterogeneous elements out of which an entity like a scientific fact is composed: biological specimens, laboratory equipment, scientific theories, novel hypotheses, academic journals, research protocols, conference presentations, business contracts, funding grants, patent law, ethical guidelines, industry partners, personal rivalries, skilled technicians, and much more (Latour, 1987; Latour \& Woolgar, 1986). It also illustrates how the scientific domain is actually a mixture of science, economics, politics, law, technology, and ethics. Thus, Latour's sensitivity to hybridity helped us similarly register the heterogeneous elements and practices assembled together to compose Healthier. Happier.

The third feature of Latour's metaphysics we drew on in this study is the concept of a mode of existence. Together, the principles of relationalism and hybridity make it possible to describe how an entity is assembled and out of what it is composed. However, they are not able to define the internal logic of specific kinds of network and networking. In other words, they are unable to help a researcher grasp why the entities produced in a scientific laboratory are different from those produced in a court of law, a house of parliament, or a work of fiction, despite their common hybridity and relationality. 
According to Latour, what accounts for these ontological differences are the modes of existence specific to each. From his perspective, a mode of existence is like a musical key-the scale upon which a composition is based. As de Vries (2016) explains, "Listening to a piece of music, someone well-versed in music will know the key the piece is played in and he will know when it's played in the wrong key; likewise, a music teacher may say that it should be played in a specific way" (p. 155). An attunement to modes of existence, therefore, provided us a means of both detecting and evaluating the compositional logic of Healthier. Happier. Having a conceptual tool of this kind allowed us to identify and avoid what Latour terms category mistakes-attempts to create or judge entities using the wrong metaphorical key, such as critiquing religious beliefs in relation to scientific principles. Using these ideas, therefore, helped us think about the prospects of critical health evidence feature in purportedly evidence-based campaigns.

By Latour's reckoning, each mode of existence is defined by five characteristics. The first characteristic is its specific hiatus. Hiatuses are the metaphorical hurdles an entity needs to overcome to continue existing across time. The second characteristic of a mode of existence is its specific trajectory. A trajectory is the unique vector created by an entity through its relations and processes of interdefinition. The felicity condition specific to the mode of existence is the third characteristic. Felicity conditions provide the criteria for judging the networked elements and relations of an entity. The specific being instituted or brought into existence by a given mode is the fourth characteristic. The final characteristic is the alteration of being a mode of existence permits. This characteristic specifies the kind of changes to which a mode of existence subjects an entity. In the next section, we explain characteristics that define the technological mode of existence with which we are concerned.

\section{Making the beings of technology visible}

In An Inquiry into Modes of Existence, Latour identifies fifteen distinct modes that he suggests characterise modernity. Latour derives these modes from interpretations of his own and others' 
research. Among the fifteen is what he terms, with a nod to Gilbert Simondon (2017), the technological mode of existence. As the name indicates, this mode provides the interpretative key for properly apprehending the mass of technological entities that shape and are shaped by the Moderns. Possessing this key is important to Latour for two reasons. The first pertains to visibility and Latour's contention that Western civilisation tends to take for granted the significant role that technologies play in everyday life, particularly in relation to the delegation of work. The second reason concerns the challenges of analysing the relationship between the Moderns and their technologies, such as the complex ways in which designers, users and technical objects create, maintain and transform themselves and each other over time.

The methodology Latour advocates for grappling with these challenges is a synthesis of an approach developed in earlier work (Latour, 1987, 1992, 1996) and the metaphysics outlined above. Using this methodology requires the researcher to examine a technology as it encounters a trial, controversy or crisis (Akrich \& Latour, 1992). These circumstances consist of situations where: a technology is used by someone for whom it is novel; a technology fails to work as intended; a technology's design, development and dissemination can be traced; and/or taken-for-granted elements of a technology's use are revealed through deliberate misuse. Each of these situations make visible the technological mode of being as well as its unique characteristics-as we shall explain.

Latour deduces that the beings instituted by the technological mode of existence are delegations, arrangements and inventions aimed at creating displacements of action, "not to do something, but to have something done" (Latour, 2013, p. 229, original emphasis). According to Latour, this displacement of action is achieved by folding together diverse components of varying resistance, duration and durability. These labyrinthine foldings are the alterations permitted within this mode of existence. Yet, while the constituent elements of these networks "lend themselves" to being folded into the arrangement, "they nevertheless remain 'themselves,' ready to let go at the slightest pretext" 
(Latour, 2013, p. 225). Thus, Latour (2013) notes, "everything that has been set up can be broken down" (p. 214). Technological beings, therefore, confront an obstacle course of hiatuses they must negotiate to move from one time, place or stage of development to the next. Accordingly, the felicity condition proper to the technological mode of existence is whether each addition to the network makes it more effective and better suited to doing what it is "made to do" (Latour, 2013, p. 227). The constant adjustments, rectifications and workarounds entailed by this requirement to innovate, coupled with the occasional false starts and restarts well known to artisans, engineers and project managers the world over, produce a trajectory of unpredictable zigzags of ingenuity and invention. And so, Latour (2013) concludes, "in the vicinity of a technological being, nothing goes straight, everything is done on the bias-and sometimes, even, everything goes askew" (p. 224).

In the next section, we use this approach and its associated conceptual apparatus to study a single public health campaign. The data upon which the investigation is based comes from three sources: campaign materials (e.g. campaign website, stakeholder letter) obtained in the course of our research and the literature to which these documents refer (see Lee, Williams \& Sebar, 2018); field notes produced through an auto-ethnography of engaging with one element of the campaign (the Health and Fitness Age Challenge app); and, interviews with six key informants integral to the development and delivery of the campaign. These informants were four members of the Queensland Government's Department of Health—two from each of the relevant departmental units-as well as one representative each from the market research company and the creative agency involved in the campaign.

Using these data, we were able to make visible the trajectory of the campaign, its various components, the work involved in assembling these components and the obstacles that had to be overcome to ensure the campaign's ongoing existence. Given the innovations inherent in the campaign, we did so, first, by conceiving the campaign as a novel technology. Second, we used our 
interview and document analysis data to trace the campaign's history. Last, through an autoethnography of the Health and Fitness Age Challenge, we attended to failing and taken-for-granted aspects of the campaign through deliberate use and misuse of the app. As we will argue towards the end of the chapter, the benefit of taking this approach is to prompt reflection on the possibilities of composing the campaign otherwise-out of other elements or through different processes—in light of its mode of existence.

\section{Describing the public health campaign}

Healthier. Happier. is a preventive health initiative of the Queensland Government. Launched in 2013, it aims to reduce population levels of overweight and obesity by changing the physical activity practices and dietary behaviours of Queensland adults. To date, the campaign has had three phases, though our research studied only the first and second ones. The aim of Phase 1 was to have Queenslanders personalise the issue of overweight and obesity and recognise problematic personal habits and actions. The aim of Phase 2 was to help people modify behaviours identified as unhealthy in Phase 1 . The aim of Phase 3 has been to continue encouraging and supporting these behaviour changes with a specific focus on food consumption. The campaign, thus, conceives of individuals as self-responsible and at-risk and in need of help and support if they are to successfully negotiate an environment understood as inherently obesogenic.

The campaign has pursued these aims using a social marketing approach in which commercial or business techniques like advertising are used to sell the benefits of behaviour change and enhance individual and collective health accordingly (Talbot \& Verrinder, 2014). All three phases have been supported by television, online, outdoor and print advertising. A campaign website (Department of Health, 2018a) containing tools, information and resources (such as "how-to" videos), has also been a central feature of these phases. Since the campaign's launch, one of the main tools on this website has been the Health and Fitness Age Calculator (Department of Health, 2018b). This tool uses an algorithm 
to convert user-entered data about weight, height, age, physical activity levels, sedentary behaviours, and food consumption into a personal Health and Fitness Age. By comparing it to users' chronological age, the campaign's designers intended this metric to serve as motivation for individuals to change behaviours deemed unhealthy. All the Phase 1 advertising referred to the concept of a person's Health and Fitness Age and directed people to the campaign website. During the next phase of the campaign, the Health and Fitness Age Calculator was incorporated into the campaign's second major tool: the Health and Fitness Age Challenge app (no longer available). This piece of smartphone software allowed users to calculate their Health and Fitness Age and then take a four-week challenge designed to help them become younger, from the perspective of the metric. Once the challenge is initiated, users receive regular alerts and tips from a virtual personal trainer. These interactions are tailored to the specific physical activity and/or dietary behaviours identified as problematic by the Health and Fitness Age Calculator. Every day of the challenge, the app also prompts users to record their progress regarding these behaviours.

In the following section we analyse Healthier. Happier. as a technological being. To do this we attend to the specific characteristics of the technological mode of existence as they manifest in the campaign. This conceptual apparatus provides access to the interpretive key with which to better understand the often opaque and taken-for-granted process of evidence-based practice in public health pedagogies like Healthier. Happier.

\section{Analysing Healthier. Happier. as a technological being}

Recall that the beings instituted in the technological mode of existence are delegations, arrangements and inventions designed to create displacements of action. In the case of Healthier. Happier. it is the Queensland Government that is seeking to "have something done" (Latour, 2013, p. 229, original emphasis). As they note on the campaign website, "64\% of Queenslanders are overweight or obese, with $33 \%$ of us not even realising it," while among the remaining 36 percent of the population, "23\% are 
at risk of being overweight in the future" (Department of Health, 2018c, para. 2). Thus, through the campaign, the Government is attempting to change these population-level health data and make "Queensland the healthiest state" (Department of Health, 2018c, para. 1). The campaign-astechnological-being seeks to achieve these population-level changes by encouraging individual Queenslanders to make "small changes" to how many serves of fruit and vegetables they eat, how large their meals are, how many sugary drinks they consume, how long they spend sitting, and how much physical activity they engage in on a daily basis (Queensland Health Preventive Health Unit, Stakeholder Letter, 28 March 2014, p. 1).

The campaign-as-technological-being entails manifold delegations and inventions. For example, it is characterised by at least three significant delegations. First, it delegates to individuals the power to change population-level health through their personal actions. Second, it delegates to the Health and Fitness Age concept the power to motivate individual behaviour change. Third, it delegates to the Health and Fitness Age Challenge smartphone app the ability to remind people how to behave and monitor their conduct. Delegating this work required the invention of the Health and Fitness Age metric, the Health and Fitness Age Calculator, the Health and Fitness Age Challenge app, the campaign advertising material plus the campaign website and its accompanying educational resources, none of which existed prior to the launch of the campaign. Indeed, prior to Healthier. Happier., the Queensland Government had never delivered an obesity prevention campaign addressing dietary behaviours and physical activity participation simultaneously.

These delegations, and the inventions that made them possible, were built upon a series of important arrangements. Healthier. Happier. was the first time the Department of Health had developed and delivered a large-scale social marketing campaign as a collaboration between departmental units and outside agencies. Together, these groups consisted of the Department's Preventive Health Unit (PHU) and its Marketing and Online Communication Unit (MOCU), as well as the 
market research company and the creative agency that won the tenders for the campaign and its associated background research and target audience testing. As we illustrate below, the division of labour this set of intra- and inter-organisational relations created was complex and contested, yet, productive.

Bringing the campaign into existence, and allowing its various delegations, arrangements and inventions to circulate, required the creative folding together of a heterogeneous network of entitiesin other words, alterations. Given the scale and sophistication of Healthier. Happier., a comprehensive list of these components would be enormous and well beyond the scope of this chapter. Here, we limit ourselves to cataloguing a selection of the constituents most heavily implicated in the alterations that formed the trajectory of the campaign.

Some of these elements have already been introduced. For example, the campaign's social marketing strategy folded together television, online, outdoor and print advertising, as well as the tools, information and resources of the campaign website and the campaign app. Furthermore, Healthier. Happier. mixed initiatives aimed at promoting both physical activity and healthy eating within the one intervention. And, third, developing the campaign entailed assembling together staff from the Department's preventive health and marketing and online communication, as well as staff beyond the Department from the market research company and creative agency.

Other key components of the campaign-as-technological-being have not yet been added to our account. The most significant of these components was data mobilised as evidence. Broadly, two kinds of data were used to inform, justify and evaluate the campaign. The first was data generated through the knowledge practices of market research. These data were collected by the market research company, who had already been engaged by the Australian Department of Health to review the existing national obesity prevention campaign and to identify key influences on health behaviours. The company was then commissioned to collect a booster sample of these data in Queensland and 
subsequently, to evaluate the effectiveness of Healthier. Happier.'s various stages. The national data set and the state booster sample began with a large-scale, multi-method, qualitative investigation involving observation, interviews and video diaries in which participants recorded their food consumption and physical activity behaviours. The findings of this investigation were then used to create a quantitative survey of population-level body mass index, food consumption and physical activity measures, along with attitudinal profiling. These data were used as benchmarks for population segmentation based on the exhibition (or not) of healthy diet and exercise behaviours and the degree of likelihood to change.

The second kind of data used in the campaign were those produced through epidemiological and public health knowledge practices. The majority of these data came from descriptive, in-house research conducted by the Department for its own use (Lee et al., 2018). Very little of it pertained to public health interventions designed to reduce the prevalence and incidence of obesity or the behaviours associated with it. The most prominent sources were the fourth report of Queensland's Chief Health Officer (CHO) (Queensland Health, 2012) and a PHU technical report (Department of Health, 2013). Other conspicuous data sources of this kind included the Australian guidelines on physical activity, sedentary behaviour and healthy eating.

As we noted earlier, successfully folding together these alterations to sustain the ongoing existence of a technological being is a continuous task-one that inevitably encounters obstacles or hiatuses. An extensive account of the many obstacles Healthier. Happier. has negotiated during its existence—like changes of government, ministerial priorities, and funding—would exceed the space afforded us. Instead, we present, here, an illustration of just two hiatuses encountered by the campaign-as-technological-being, how these hiatuses were traversed through adjustments, rectifications and workarounds typical of the technological mode of existence, and the effects of these measures on the campaign's trajectory. 
The first hiatus was encountered at the very beginning of the campaign's existence. From the State Government's perspective, Queensland had an obesity problem. Accordingly, the Minister and the $\mathrm{CHO}$ were committed to a new anti-obesity campaign. Reflecting the priority they gave this issue, both wanted to play a key role in designing and approving the campaign's messages, focuses and strategies. To this end, both wanted to buy a "shock tactics" campaign from another state based on a "toxic fat" concept. Indeed, content from the toxic fat campaign was showcased at the internal launch of the initiative, negotiations over its use having already begun. However, within MOCU and PHU, those responsible for developing and delivering the campaign opposed the "toxic fat" campaign's use of guilt and fear.

The workaround deployed in this instance was the folding in of bureaucratic procedure. In Queensland, an independent governmental communication committee must approve all government advertising. Approval from this committee is contingent on the advertising passing rigorous market testing of its suitability for a Queensland audience. As suspected by those with reservations about it, the "toxic fat" campaign did not test well when referred to this committee. The test audiences identified obesity as a sensitive and emotive issue. Instead, this group indicated a strong preference for positive, supportive behaviour change messages that were not focused on weight. Faced with these findings, the $\mathrm{CHO}$ decided to abort the "toxic fat" campaign, start over and develop a new, Queensland-specific campaign. The effect of this adjustment on the trajectory of the campaign was two-fold. First, it momentarily shifted the locus of control over campaign messages from the upper echelons of the Department to a sample of the electorate. In so doing, it changed the campaign's direction from the "toxic fat" concept to an obesity prevention campaign where the strategies avoided using the word "obesity."

A second hiatus was the relationship between PHU and MOCU, which was marked on both sides by perceptions of "us" and "them" early in the campaign. Differing knowledge practices were the 
most significant cause of these difficulties. Within PHU, epidemiological knowledge and concerns with evidence-based medicine dominated. From their perspective, the Government maintained its credibility as a source of health information through these knowledge practices. By contrast, within MOCU, market testing, message cut-through and the maximisation of return on investment were paramount. The hurdle created by this philosophical divergence was exacerbated by: the geographical separation of the two units (MOCU was located in the Brisbane CBD, whereas PHU was located four kilometres away in Brisbane's inner-North); the departmental division of labour (PHU held the budget and were responsible for the approval of campaign content, whereas MOCU tested ideas, content and messages with the target audiences); and, different intra-organisational processes (MOCU approval procedures were perceived as being faster and less cumbersome than PHU ones).

This obstacle was ultimately cleared by a series of syncretic foldings whereby heterogeneity was homogenised, domesticated and rendered commensurable (Law et al., 2014). For example, key MOCU staff began working in PHU offices one day each week to ensure easier communication between units. Furthermore, key staff in both units agreed to make the $\mathrm{CHO}$ report and relevant national guidelines the authoritative point of reference in any situation where each unit's knowledge created mixed messages about "the obesity problem in Queensland" or the means by which the campaign should try to solve it. These foldings created the felicity conditions by which entities were added, rearranged, and readjusted so that the campaign was able to continue to exist in a particular way. For instance, they routed the campaign through epidemiological data and national guidelines. These foldings also biased the campaign towards knowledge transmission approaches to behaviour change. Here too, then, the campaign's trajectory zigzags in response to efforts to stabilise its existence.

\section{The Value of Modes of Existence}

We opened this chapter with a quote from one of our PHU informants. In it, he responds to a question we posed about what prompted the Healthier. Happier. campaign. He goes on to list a range of factors 
beyond the epidemiological data, such as the availability of funding, public perceptions of the issue, political will, and so on. It is tempting to interpret this quote as illustrating of how campaigns like Healthier. Happier. get biased by political, technological or other forces. And, it is enticing to think public health campaigns might be more efficacious and more just if they applied the knowledge that is currently excluded (particularly the critical public health kind). However, Latour's work on modes of existence has helped us think about the campaign's existence in ways other theories have not. Specifically, it has benefited us in three related ways.

First, this conceptual apparatus sensitised us to the campaign's existence as a technological being. In so doing, our analysis eschewed anthropocentric or technocentric approaches in which primary attention is given to the ways humans shape their tools or tools shape humans. Instead, we were able to attend to the campaign's ontologically diverse constituents symmetrically and simultaneously. By de-centring humans in this way and highlighting hybridity, Latour's metaphysics are very much part of the ontological turn and the contemporary posthuman moment (Pickering, 2017).

Second, Latour's thinking helped us avoid the category mistake of interrogating the campaign in the wrong metaphorical key. For Latour, each mode of existence is valuable in its own right. There is no single mode in Latour's worldview to which we can defer for arbitration when values conflict (such as disputes about what counts as evidence in evidence-based-practice). Each mode needs to be addressed in its own terms and is irreducible to any other. We argue that Healthier. Happier is not a scientific entity, nor a political entity, but rather, a technological entity and should be judged as such.

Third, Latour's explication of the technological mode of being has attuned us to issues implicated in attempts to increase public health campaign developers' engagement with critical public health literature. The question of why critical health research is seldom translated into practice by policy makers and practitioners vexes us. Analysing Healthier. Happier. as a technological being drew our attention to the compositional logic of the campaign's existence. The consequences of attempting 
to fold critical public health knowledge into a campaign like Healthier. Happier. is an open, empirical question. Nevertheless, it is a question whose answer would benefit greatly from grappling with whether such a folding would satisfy the felicity conditions proper to the technological mode and how it might affect the hiatuses encountered by the campaign, the trajectory of the campaign and so on. As we showed, the construction and incorporation of evidence was already a point of considerable turbulence and instability and we have doubts about the prospects of critical public health evidence to stabilise these dynamics without considerable attention being given to the complexity of these dynamics.

In this chapter, we have sought to study a public health campaign as a technological being and to highlight the characteristics unique to its mode of existence. Along the way, we have employed a mere fraction of Latour's extensive and complex philosophical project. We have not, for example, been able to address the beings of other modes of existence (like politics and law) whose path the campaignas-technological-being crosses. Nor have we been able to explore the "labyrinth of unanticipated consequences" (Latour, 2013, p. 221) the twisting trajectories of public health campaigns leave in their wake. Hopefully, however, we have highlighted some of the utility of Latour's worldview for researchers interested in grappling with new ways of engaging with health education. Moreover, we hope we have hinted at the broader "compositionist agenda" (Latour, 2010) that lies at its heartnamely, the difficult, but necessary diplomatic task of composing and inhabiting a common world shared by those human and nonhuman Others whose existence and franchise modernity has routinely denied or ignored (see Hokowhitu, 2014; Taylor, Wright \& O’Flynn, 2016).

\section{Further Reading}

de Vries, G. (2016). Bruno Latour. Cambridge, United Kingdom: Polity Press. 


\section{References}

Akrich, M. \& Latour, B. (1992). A summary of a convenient vocabulary for the semiotics of human and nonhuman assemblies. In W. E. Bijker \& J. Law (Eds.), Shaping technology/building society: Studies in sociotechnical change (pp. 259-264). Cambridge, MA: The MIT Press.

de Vries, G. (2016). Bruno Latour. Cambridge, United Kingdom: Polity Press.

Department of Health. (2013). Measured obesity in Queensland 2011-12. Retrieved from:

https://www.health.qld.gov.au/_data/assets/pdf_file/0015/442140/measured-obesity.pdf

Department of Health. (2018a). Healthier.Happier. Retrieved from:

https://www.healthier.qld.gov.au/?gclid=EAlalQobChMI69G6_bGR3gIVVyOrCho1EOGzEAAYASAAEgL 7ZvD_BwE

Department of Health. (2018b). Calculate your health and fitness age. Retrieved from:

https://www.healthier.qld.gov.au/calculator/\#/calculator

Department of Health. (2018c). About Healthier. Happier. Retrieved from:

https://www.healthier.qld.gov.au/about/

Hokowhitu, B. (2014). If you are not healthy, then what are you? Healthism, colonial disease and bodylogic. In K. Fitzpatrick \& R. Tinning (Eds.), Health education: Critical perspectives (pp. 31-47). London, United Kingdom: Routledge.

Latour, B. (1987). Science in action: How to follow scientists and engineers through society. Cambridge, MA: Harvard University Press

Latour, B. (1988). The Pasteurization of France (Trans. A. Sheridan \& J. Law). Cambridge, MA: Harvard University Press.

Latour, B. (1992). Where are the missing masses? The sociology of a few mundane artifacts. In W. E. Bijker \& J. Law (Eds.), Shaping technology/building society: Studies in sociotechnical change (pp. 225258). Cambridge, MA: The MIT Press. 
Latour, B. (1993). We have never been modern (Trans. C. Porter). Cambridge, MA: Harvard University Press.

Latour, B. (1996). Aramis or the love of technology (Trans. C. Porter). Cambridge, MA: Harvard University Press.

Latour, B. (2005). Reassembling the social: An introduction to actor-network theory. Oxford, United Kingdom: Oxford University Press.

Latour, B. (2010). An attempt at a "compositionist manifesto." New Literary History, 41(3), 471-490. Latour, B. (2013). An inquiry into modes of existence: An anthropology of the moderns (Trans. C. Porter). Cambridge, MA: Harvard University Press.

Latour, B. \& Woolgar, S. (1986). Laboratory life: The construction of scientific facts ( $2^{\text {nd }}$ ed.). Princeton, NJ: Princeton University Press.

Law, J., Afdal, G., Asdal, K., Lin, W.-Y., Moser, I., \& Singelton, V. (2014). Modes of syncretism: Notes on noncoherence. Common Knowledge, 20(1), 172-192. doi: 10.1215/og61754X-2374817

Lee, J., Williams, B., \& Sebar, B. (2018). Tracing translations: The journey from evidence to policy to physical activity promotion campaigns. In J. Piggin, L. Mansfield, \& M. Weed (Eds.), The Routledge handbook of physical activity of physical activity policy and practice (pp. 139-152). London, United Kingdom: Routledge.

Pickering, A. (2017). The ontological turn: Taking different worlds seriously. Social Analysis, 61(2), 134150. doi: 10. 3167/sa.2017.610209

Queensland Health. (2012). The health of Queenslanders 2012: Advancing good health. Fourth report of the Chief Health Officer Queensland. Retrieved from:

https://www.health.qld.gov.au/_data/assets/pdf_file/0027/442278/cho-report-2012.pdf

Simondon, G. (2017). On the mode of existence of technological objects (C. Malaspina, Trans). Minneapolis, MN: University of Minnesota Press. 
Talbot, L. \& Verrinder, G. (2014). Promoting Health: The primary healthcare approach. Sydney, Australia: Elsevier.

Taylor, N., Wright, J., \& O'Flynn, G. (2016). HPE teachers' negotiation of environmental health spaces: Discursive positions, embodiment and materialism. Australian Educational Researcher, 43, 361-376. doi: $10.1007 / 513384-016-0205-8$ 